stimuli for varying amounts of time, and thus yield more precise measures of the relative contributions of each of these classes of stimuli to the prevailing AL of the numerical stimulus set.

\section{REFERENCES}

Capehart, J., \& Pease, V. An application of adaptation-level theory to transposition responses in a conditional discrimination. Psychonomic Science, 1968, 10, 147-148.

Cicchetti, D. V. Extension of multiple-range tests to interaction tables in the analysis of variance: A rapid approximate solution. Psychological Bulletin, 1972, 77, 405-408.

Fairbank, B. A., Jr., \& Capehart, J. Decision speed for the choosing of the larger or the smaller of two digits. Psychonomic Science, 1969, 14, 148.

Helson, $\mathrm{H}$. Adaptation level theory, An experimental and systematic approach to behavior. New York: Harper \& Row, 1964.

Moyer, R. S., \& Landauer, T. K. Time required for judgment of numerical inequality. Nature, 1967, 215, 1519-1520.

(Received for publication October 7, 1974.)

Bulletin of the Psychonomic Society

1975, Vol. 5 (1), 20-22

\title{
Forward and backward associations among serial list items*
}

\author{
J. D. RE AD \\ University of Lethbridge, Lethbridge, Alberta, Canada T1K $3 M 4$
}

\begin{abstract}
Following serial learning, a paired-associates learning task in which the pairs were comprised of adjacent serial list items assessed the relative strengths of forward and backward associations between pair members. In addition, either one or two items served a stimulus function within the pairings. The results suggested that forward associations were relatively stronger at the beginning of the serial list than backward associations and that the reverse of this relationship was true over the latter half of the serial list. Moreover, the results suggested that compound associations were relatively stronger over the last half of the serial list than two-item associations, and the reverse of this relationship was true at the beginning of the serial list. The results were related to Lashley's (1951) interpretation of sequential behavior.
\end{abstract}

Throughout the history of research concerned with the associations formed between members of a serial list, backward associations have generally been neglected in favor of an interest in forward associations. For example, in virtually all of the serial learning (SL) to paired-associates learning (PAL) and PAL to SL transfer studies designed to test hypotheses about the functional stimuli in SL, construction of the transfer lists was based upon presumed forward associations between serial item or positions. However, in those studies using

*This research was supported by Grant A8350 from the NThis research was supported by Grant A8350 from the Lethbridge Research Grant 28-1069. The author wishes to thank Stuart Travis and Richard Peterson for their assistance in data collection. Requests for reprints should be sent to J. D. Read, Department of Psychology, University of Lethbridge, Lethbridge, Alberta, T1 K 3M4. double-function PA lists, the generally slower learning and negative transfer effects observed of ten have been attributed to the theoretical presence of backward associatons which arise as a result of PA items serving both stimulus and response functions (e.g., Postman \& Stark, 1967). As yet there have been no investigations of the relative strengths of forward and backward associations at the conclusion of an SL task.

In his classical paper on the problem of serial order in behavior, Lashley (1951) expressed his belief that the individual components of a verbal or motor activity are determined more by the idea to be expressed or the intention to act than by the specific chain of successive stimuli and responses. In other words, if that which has yet to be expressed determines in some way that which precedes it, an extension of Lashley's hypothesis to a verbal SL task might suggest that those items in 
positions which follow a particular item may come to serve, in part, as stimuli for the recall of that item. For example, in a serial list where the items are represented as $A-B-C-D-E$ etc., the sufficient stimuli for recall of $C$ may include $D$ (or the position held by this item) as well as B (or its position). If this is the case, it would be predicted that backward associations would exist between items and that the strength of these associations might vary as a function of serial position. Specifically, since SL proceeds from the ends of the list toward the middle, one would anticipate that forward associations would be strongest at the beginning of the list and become relatively weaker in comparison to backward associations. The reverse of this gradient would be predicted for backward associations. Since Lashley emphasized the unity of well learned, almost automatic serial activities, it seems doubtful that the present extension of the hypothesis would apply to early stages of SL. Therefore, primary interest in the experiment was focused upon the relative strengths of forward and backward associations at the completion of SL.

In addition, it is likely that forward and backward associations involve more items than the one preceding or following item in SL. Indeed, on the basis of studies by Battig, Brown, and Schild (1964) and Posnansky (1972) there is evidence which suggests that the likelihood of compound associations between items is greater near the middle than the ends of a serial list. To test the generality of these findings, the single and compound associations in both directions were also compared in the experiment.

\section{METHOD}

\section{Subjects}

One hundred eighty first- and second-semester psychology students served for extra class credit. The experiment was completed in groups of four to eight Ss.

\section{Materials, Design and Procedure \\ Two 12-item serial lists, equivalent in rated imagery and meaningfulness, were constructed of common nouns drawn from the Paivio, Yuille, and Madigan (1968) norms. A total of eight groups served in the experiment and consisted of four experimental $(\mathrm{Ns}=17)$ and four control $(\mathrm{Ns}=10)$ conditions. All Ss practiced on a serial list for 10 anticipation trials and then transferred to a PAL task. The PA items used in the transfer lists were constructed by pairing adjacent items from the serial list. For the experimental Ss, the PA lists were made up of the same items as their serial list; for the control Ss a different serial list was used but these Ss received the identical PA lists as the experimental Ss. The control groups were included to insure that pair difficulty was equivalent across serial positions within each transfer condition.}

Four six-pair lists were constructed from the serial lists such that adjacent serial list items comprised the pairings and that the response terms were the same in all conditions. That is, if the serial list is designated as $\mathrm{A}-\mathrm{B}-\mathrm{C}-\mathrm{C}_{-} \mathrm{L}$ and italics are used to designate the response term in each pairing, the four PA lists were constructed as follows. First, in order to assess the strength of forward $(F)$ associations between one serial item and the next (Conditon F1), the six pairs were $A-\underline{B}, C-\underline{D}, E-\underline{F}, G-\underline{H}, I$ $-\underline{J}$, and $\mathrm{K}-\underline{\mathbf{L}}$. Secondly to determine the strength of the forward association between the two preceding items and the next (Condition F2), the pairings were $\mathrm{L}-\mathrm{A}-\underline{\mathrm{B}}, \mathrm{B}-\mathrm{C}-\underline{\mathrm{D}}, \mathrm{D}$ $-\mathrm{E}-\underline{\mathrm{F}}, \mathrm{F}-\mathrm{G}-\underline{\mathrm{H}}, \mathrm{H}-\mathrm{I}-\underline{\mathrm{J}}$, and $\mathbf{J}-\mathrm{K}-\underline{\mathrm{L}}$. Third, to assess the strength of the backward $(\vec{B})$ associations between one item and the one which followed it (Condition B1), the following pairs were used: $\underline{B}-\mathrm{C}, \underline{\mathrm{D}}-\mathrm{E}, \underline{\mathrm{F}}-\mathrm{G}, \underline{\mathrm{H}}-\mathrm{I}, \underline{\mathrm{J}}-\mathrm{K}$, and $\underline{\mathrm{L}}-\mathrm{A}$. Finally, to assess the strength of the backward association between one item and the two which followed it (Condition B2), the pairings were $\underline{B}-\mathrm{C}-\mathrm{D}, \underline{\mathrm{D}}-\mathrm{E}-\mathrm{F}, \underline{\mathrm{F}}-\mathrm{G}-\mathrm{H}, \underline{\mathrm{H}}-\mathrm{I}-\mathrm{J}$, $\underline{J}-\mathrm{K}-\mathrm{L}$, and $\underline{\mathrm{L}}-\mathrm{A}-\mathrm{B}$. The items which comprised the pairings were presented together for study on a single slide in a vertical order which corresponded to their order in the serial list. On test trials, the response term was deleted. Thus, for example, Condition F2 Ss received the pairing $\mathrm{L}-\mathrm{A}-\mathrm{B}$ on study trials and $\mathbf{L}-\mathrm{A}$ - Blank on test trials. Ss in Condition B2, on the other hand, received B - C - D on study and Blank - C - D on test trials.

During SL the items were presented one at a time for $6 \mathrm{sec}$ and Ss recorded their responses on numbered sheets. An asterisk served to indicate the beginning of the list and two blank spaces filled the intertrial interval. The instructions emphasized that only the item which followed the one presented was to be recorded and that a line should be drawn through the appropriate space when no response was made. During PAL experimental Ss received a single test trial plus two study-test trials. Control Ss, on the other hand, received three complete study-test trials. Ss recorded their responses on numbered sheets and materials were presented in predetermined random sequences at a 5 -sec rate on both study and test trials with $10 \mathrm{sec}$ intra- and intertrial intervals. Since the interest in the experiment primarily involved the utilization of serial information during PAL, experimental Ss were informed as to the manner by which the pairings had been constructed.

\section{RESULTS}

\section{Serial Learning}

Separate analysies of variance were completed using as data the total numbers of errors made in each serial position for the control and experimental Ss. Since the variables of stimulus direction and number of stimuli were essentially irrelevant during SL, no differences were anticipated between the conditions on these variables. The assumption of equivalence was supported by the observation of essentially identical means between groups within both the experimental and control conditions, all Fs $<1$. As expected, the serial position curve was evident in all groups and led to significant main effects of serial position, Fs $>49.18, p<.001$. There were no other significant effects in these analyses, Fs $<1$. The numbers of experimental Ss not reaching a criterion of one errorless trial in Conditions F1, F2, B1, and B2 were 1, 3, 1, and 3, respectively. However, all of these Ss had responded correctly to every serial position at least once.

\section{Paired-associates Learning}

The numbers of total errors made on each pair as a function of the serial position held by the pair during SL were tabulated separately for the control and experimental Ss. The mean numbers of total errors made by the control Ss in Conditions F1, F2, B1, and B2 were, respectively, 5.50, 13.30, 4.50, and 13.70 . In an analysis of these data, the superiority of the 


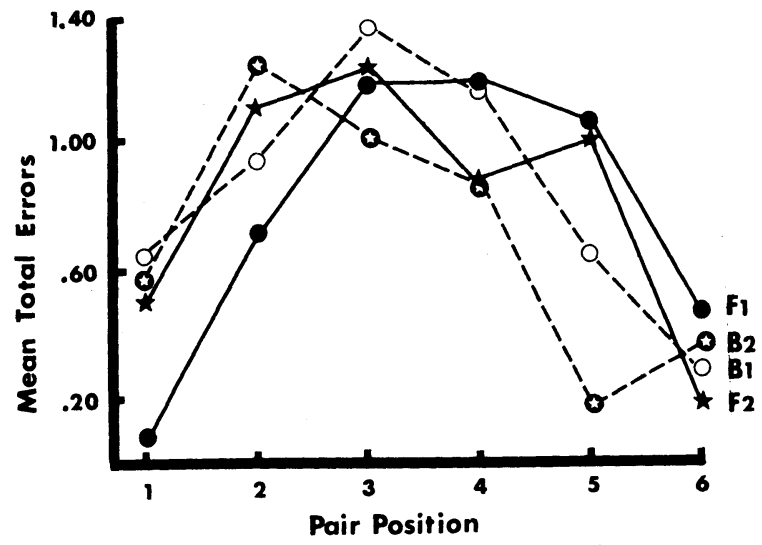

Fig. 1. Mean total errors made in each experimental conditions during PAL as a function of serial position held by the pairs during $\mathbf{S L}$.

one-stimulus over the two-stimulus groups was highly significant, $F(1,36)=84.96, p<.001$. It should be noted that the $\mathrm{F} 2$ and $\mathrm{B} 2$ conditions received double function as compared to the single-function PA lists of $\mathrm{F} 1$ and $\mathrm{B} 1$. The slower acquisition of double-function lists has been previously well documented in the literature. It is likely, however, that an additional contributing factor to interference was present in Control Conditions F2 and B2, since each study slide consisted of three rather than two items. Although performance on the six individual pairings was consistent across the four control groups, the main effect of pairings was significant, $\mathrm{F}(5,180)=3.57, \mathrm{p}<.01$. That is, all pairings which contained the response term which held the second serial position during SL produced significantly fewer errors than any of the remaining pairings. In short, apart from the existence of a relatively easy item representing the first pair position in all groups, the transfer pairings presented to each experimental condition could be considered equivalent in difficulty. There were, as expected, fewer errors made on each successive test trial, which led to a significant main effect of trials, $F(2,72)=15.03, p<.001$. All other main effects and interactions were nonsignificant, Fs $<1.51, \mathrm{p}>.02$.

The mean numbers of total errors made by experimental conditions F1, F2, B1, and B2 were, respectively, $4.64,5.06,5.06$, and 4.24 . That overall performance was essentially identical between these groups is supported by nonsignificant effects of stimulus direction, number of stimuli and their interaction, Fs $<1$. In Fig. 1 the mean total errors are plotted as a function of pair position for each condition. As may be seen, all functions demonstrate the bowed serial position effect frequently observed in SL to PAL transfer data (e.g., Ebenholtz, 1966). The overall shape produced a significant main effect of pair positions, $F(5,320)=$ $11.99, \mathrm{p}<.001$. Moreover, the Stimulus Direction by Pair Position interaction was significant, which suggests a reversal in effectiveness upon recall for the forward and backward stimuli as one progresses from the beginning to the end of the serial list, $\mathrm{F}(5,320)=2.83, \mathrm{p}<.025$.
However, since the majority of this effect was produced by the differences between the forward and backward conditons at pair positions 1,2 , and 5 , these results should be interpreted with caution. Whereas one stimulus term is numerically more effective than two stimuli at the beginning of a serial list and these conditions are reversed in effectiveness over the latter half of the serial list, this interaction between the number of stimuli and pair positions fell just short of significance, $F(5,320)=1.95, p<.10$. However, individual mean comparisons revealed the one-stimulus conditions to have made significantly fewer errors on pair positions 1 and 2 but significantly more errors on pair positions 4 and 5 than the two-stimulus conditions, $\mathrm{p}<.05$. That performance improved across test trials and that the greatest gains were shown in the middle pair positions was supported by a significant main effect of trials and a significant Pair Positions by Trials interaction, Fs $>3.70, p<.01$. However, the exact nature of the gains over trials proved to be a function of experimental transfer condition and pair position as shown by a significant four-way interaction involving all variables, $F(10,640)=2.04, p<.05$. All remaining interactions were nonsignificant, $\mathrm{Fs}<1.87$, $\mathrm{p}>.05$.

\section{DISCUSSION}

The results indicated that, in terms of stimulus effectiveness upon recall, an interaction exists between stimulus direction and pair position and suggests that forward associations were relatively stronger at the beginning than backward associations and the reverse held true over the latter half of the serial list. Moreover, the results indicated that there exist compound associations in both forward and backward directions which are at least as strong as the two-item associations. Although the relevant interaction was not statistically significant, the results are suggestive that such compound associations are relatively stronger over the last half of the serial list than the two-item associations and that the reverse of this relationship holds true at the beginning of the serial list. Previous investigations by Batting et al (1964) and Posnansky (1972) have found more conclusive evidence of the greater strength of compound associations in the middle rather than at the ends of a serial list. Taken together, the results support the extension of Lashley's (1951) hypothesis to a verbal SL task. That is, those items which follow another item are capable of serving as stimuli for the recall of that item. However, it remains to be determined whether these same items may serve as functional stimuli during the SL task itself.

\section{REFERENCES}

Battig, W. F., Brown, S. C., \& Schild, M. E. Serial position and sequential associations in serial learning. Journal of Experim ental Psychology, 1964, 67, 449-457.

Ebenholtz, S. M. The serial position effect of ordered stimulus dimensions in paired-associate learning. Journal of Experimental Psychology, 1966, 71, 132-137.

Lashley, K. S. The problem of serial order in behavior. In L. A Jeffress (Ed.) Cerebral mechanisms in behavior. New York: Wiley, 1951.

Paivio, A., Yuille, J. C., \& Madigan, S. Concreteness, imagery and meaningfulness values for 925 nouns. Journal of Experimental Psychology Monograph Supplement, 1968, 76,(1,Pt.2).

Posnansky, C. J. Proving for the functional stimuli in serial learning. Journal of Experimental Psychology, 1972, 96, 184-193.

Postman, L. \& Stark, K. Studies of learning to learn. IV. Transfer from serial to paired-associate learning. Journal of Verbal Learning and Verbal Behavior, 1967, 6, 339-353.

(Received for publication September 3, 1974.) 